\title{
The Effect of Pressure-Induced Flow (PIF) Processing on the Thermal Stability and Mechanical Properties of Ultra-High Molecular Weight Polyethylene (UHMWPE) Gel
}

\author{
Musa E. Babiker, Wang Guangcheng, Zhang Sen, Tang Yi Fei, Peng Yuqing, Rong Huaiping \& Yu Muhuo \\ State Key Laboratory for Modification of Chemical Fibers \& Polymer Materials \\ College of Material Science \& Engineering, Donghua University \\ Shanghai, P.O. Box 201620, China
}

Tel: 86-21-6779-2887_E-mail: yumuhuo@dhu.edu.cn

\begin{abstract}
A new method using gel-swelling state and pressure-induced flow (PIF) will be presented for obtaining high-performance materials of ultra high molecular weight polyethylene (UHMWPE), which is available for the production of high-strength and high-modulus materials. The effect of PIF on the thermal stability and mechanical properties UHMWPE gel state has been investigated using four kinds of gel formed from 4, 6, 8 and $10 \%$ of UHMWPE. The microstructures of UHMWPE gel were studied by using scanning electron microscope (SEM). The thermal and mechanical properties of the UHMWPE gel were investigated by thermogravimetric analysis (TGA), diffraction scanning calorimetry (DSC), dynamic mechanical analysis (DMA) and the universal test machine (UTM). The images obtained by SEM present a gel-like layers structure of UHMWPE gel sheet as a result of the deformation and re-arrangement of the gel sheets during PIF process. From the DSC, DMA and TGA results, we found that the thermal stability of the UHMWPE gel increased as the UHMWPE content increased. The thermal stability and the increase of strength are discussed with respect to the effect of PIF deformation.
\end{abstract}

Keywords: UHMWPE, Gel process, Pressure-induced flow, Thermal stability, Mechanical properties

\section{Introduction}

Gel process of ultra-high molecular weight polyethylene (UHMWPE) is by now familiar technique to obtain ultra-high strength polyethylene materials. Ultra-high molecular weight polyethylene (UHMWPE) is a thermoplastic material with an excellent set of properties, such as good abrasion resistance, the highest impact toughness of any plastic at cryogenic temperature, good corrosion resistance and environmental stress-crack resistance, a low coefficient of surface friction, and noise- and shock-abatement properties. Many applications in different areas, e.g. in mining, foundries and transportation, have been found for UHMWPE, due to its unique properties. Moreover, UHMWPE is used in medicine for the manufacture of artificial joints in most orthopaedic replacements, especially for hips and knees. (Hoogsteen et al, 1988; 1990) stated that the UHMWPE fiber can be prepared by gel spinning using general solution under a low spin draft and a low quenching temperature by appropriate extraction and drying conditions. (Pennings et al, 1990; 1986; 1983) showed the possibility of gel-spinning of UHMWPE at high speed under high extrusion rate and temperature. Maghsoud et al. (2007) stated the characteristics of UHMWPE gel spinning and the relationship between extraction and concentration of solvent with draw ratio and the orientation. However, due to the reduction of the number of entanglements compared to more concentrated systems (e.g. melt-spinning, dry- spinning and hydrostatic extrusion) better properties can be obtained. Currently, materials with an ultra high tensile strength, a young's modulus can be prepared by using this method, Ruan et al. (2006) claimed that mixing of nanostructure with UHMWPE gel lead to ultimate fiber reinforcement nanocomposites with improved mechanical properties. Yeh et al. (2008) examined the ultra-drawing gel films and UHMWPE/LMWPE blends. The addition of small amount of LMWPE to a gel film of UHMWPE, can facilitated the disentanglement of the UHMWPE molecules to get a higher draw ratio which can promote an increase in the UHMWPE molecular chain orientation and directly affected the anti-creeping properties of the gel film. Molecular gel samples are usually prepared by dissolving low molecular mass organic gelator in a liquid, usually by warming. Weiss et al. (2006) highlighted that any method used to measure the yield stress can also be utilized to devise a rheological criterion for gelation. Pakhomov et al. (2007) studied the correlation between the parameters of crystallites in gels and the drawability of gel-derived fibers. 
The results shows that the crystallites in polymer gels play a role of fixers of macromolecules needed to form the molecular network, and the amount and strength of the fixers determines a capability of the network to be transformed to regular oriented structure during the drawing process. It was found that the UHMWPE gels with the crystalline phase consisting mainly of small size $(6-7 \mathrm{~nm})$, uniform crystals are not suitable for manufacturing oriented fibers in contrast to gels with crystalline fixers built of multi-chain crystals.

Morye et al. (1999) optimized the ballistic and mechanical properties of the hot compacted materials by merely changing the compaction temperature of gel spun polyethylene. The other advantages it offers include ease of processing into complex parts and ease of recycling. The composites obtained by hot compaction and those obtained by the conventional prepreg route have similar ballistic performance they absorb energy by different mechanisms. Pakhomov et al. (2003) stated that the chain straightening process in gel-spun fibers of UHMWPE on the ends of crystallites leads to the development of quasi-ordered structure built of the straight-chain-segment (SCS) not involved into folded crystallites. The Young's modulus of the samples correlates with the thickness of the rigid entities measured along the fiber axis. Ohta et al. (1995) studied the Ultra-drawing behaviour of ultra-high-molecular weight polyethylene by comparison of the gel-like spherulite pressing method and the gel-casting method prepared from a solution of ultra-high-molecular weight polyethylene. The structural change during neck deformation was most drastic in the ultra-drawing process. The degree of orientation with respect to the drawing direction drastically increased, and the crystalline size in the direction normal to the chain axis clearly decreased during neck deformation. The fibers prepared by a regular forming technology have a folded chain structure in which the parts of molecules with order arrangement to form crystalline regions in the fiber are linked by means of a few tie-molecules between the crystalline regions. Therefore, the real tensile strength and tensile modulus are far lower than the values estimated according to the $\mathrm{C}-\mathrm{C}$ covalent bond energy. Gel spinning enables polymer molecules with very high molecular weight to disentangle sufficiently during the dissolving process and the disentangling state can be kept as-spun by quenching. When the as-spun state undergoes ultra hot drawing, the disentangled fold chain structure is easily transformed into an extended one. Since the extended chain structure has fewer molecular terminals and a higher orientation and crystallinity, the fibers possess better mechanical properties than those formed by a regular spinning technology.

\subsection{Pressure Induced Flow (PIF) Process}

Application of pressure can induce melt-like flow manners in block copolymer systems ('baroplastics'). (Gonzalez et al. 2003) Similar plastic deformation mechanisms of semi-crystalline polymers in the solid state have been investigated since the seventies (Ward et al, 1977; Bowden et al, 1974) following the development of new processing technologies and due to the requirement of improved mechanical properties of the final products. However, the re-arrangement of the gel molecules is effective because of the removal of solvent from the gel sheet. The thin and highly tuning gel sheet can be precisely controlled to achieve optimized gel sheet properties. Strobl et al. (1997) found that the deformation sequence in tension was entirely strain-controlled and practically did not depend on the temperature or deformation rate. Gonzalez et al. (2003) argued that the ability to shape plastic at low temperatures also makes it possible to mix thermally sensitive materials like biologically-derived pharmaceuticals with the material. Galeski et al. (1992) stated that the deformation in the plane-strain proceeds practically homogeneously, without any instability, while kinematically it is similar to tension, leading to axial flow of the polymer in the direction perpendicular to a compressive load. Thomas et al. (2009) provided that an estimation of dislocation kinetics for comparison with actual strain rates of homogeneous plastic deformation in polyethylene and polypropylene. The use of a deep channel-die is the approach to produce samples by compression in such a die is relatively large, sufficient for other experiments. After compression, the structure and orientation produced by plastic deformation in such large specimens could be investigated.

\section{Experimental}

\subsection{Materials}

The UHMWPE used in this study was supplied by Celanese (China) Holding Co. Ltd with (MW $=\mathrm{Mw}=5 \times 10^{6}$ $\left.\mathrm{kgmol}^{-1}, \mathrm{Mw} / \mathrm{Mn}=8\right)$ and was used as received. Paraffin oil (Shanghai- China), density $\left(20{ }^{\circ} \mathrm{C}\right)$ is $0.835-0.855$ $\mathrm{g} / \mathrm{ml}$, and boiling point at $340{ }^{\circ} \mathrm{C}$. Oxidative degradation of the polyethylene was prevented by mixing all solutions with $0.5 \mathrm{wt} \%$ (weight of paraffin oil) of antioxidant 2, 6-Di-tert-butyl-p-cresol M. p $69 \sim 71^{\circ} \mathrm{C}$. And n-hexane with density $\left(20^{\circ} \mathrm{C}\right)$ is $0.6583 \sim 0.6613 \mathrm{~g} / \mathrm{ml}$, and refractive index $1.3741 \sim 1.3761$.

\subsection{Sample Preparation}

For the gel-processing, 5 samples were prepared using the materials listed in Table 1. The recipe was dissolved in a beaker $(250 \mathrm{ml})$ with paraffin oil at $120^{\circ} \mathrm{C}$ followed by hand stirring to distribute the material in the solvent and to prevent generation of bubbles. When the temperature reached $130-135{ }^{\circ} \mathrm{C}$, a white solution of 
UHMWPE gel was formed; the stirred was stopped and the solutions were stored at $150^{\circ} \mathrm{C}$ for 48 hours and subsequently cooled slowly to room temperature.

Insert Table 1 about here

\subsection{PIF experiments}

PIF was designed as a mini-mold apparatus that acts like a channel-die system throughout this study. The PIF stages were performed using a compression tool. As shown in Figure 1 the apparatus was $120 \mathrm{~mm}$ length $(l)$ for the die (along flow direction, FD), $80 \mathrm{~mm}$ length $\left(l_{l}\right)$ for the plunger as the extensions of the sample along flow direction, $10 \mathrm{~mm}$ width as constrained direction, $\mathrm{CD}$, at a constant load $35 \mathrm{MPa}$ (along loading direction (LD)). The apparatus allows the sample to flow a long the flow direction (FD) only. The advantage of a deep mould is that the samples produced by compression in such a mould are relatively large, so that the structure and orientation produced by plastic deformation as well as the macroscopic recovery behavior could be studied easily. On the other hand, due to large lateral surface area of the sample, friction forces between the sample and mould could not be neglected, which resulted in overestimation of the stress. This was the case when the sample placed on the mould was accurately weighted prior to compression.

Insert Figure 1 about here

The size of specimens used in the PIF experiment was 10x50x30 $\mathrm{mm}^{3}$ (CD x FD x LD). All PIF experiments were performed at a constant load and at room temperature as shown in Figure 2. The residual paraffin oil was extracted by $n$-hexane at room temperature for 1 hour repeated many times until extraction reached equilibrium state.

Insert Figure 2 about here

\subsection{Extraction of the Solvent}

The following procedure was used in order to determine the extraction equilibrium. The gel sheets (after PIF) were cut into small sheets of equal lengths. Each sample was about $70 \mathrm{~mm}$ in length and $5 \mathrm{~mm}$ in width. The samples were weighted and placed into the n-hexane solution for 1 hour. Then, the samples were taken out of the solution to evaporate the $\mathrm{n}$-hexane. The samples weights were measured at several intervals of time to ensure that no weight change occurred and the n-hexane was completely evaporated from the gel sheets. Then, the gel sheets were put into the solution again for another 1 hour and the above procedure was repeated until extraction reached equilibrium state.

\section{Characterizations}

\subsection{Mechanical tests}

The mechanical properties of the HDPE gel sheets were measured using DWD electronic universal testing machine. A crosshead speed of $10 \mathrm{~mm} / \mathrm{min}$ and specimen width of $70 \mathrm{~mm}$ and thickness $1.5 \mathrm{~mm}$ were used.

\subsection{Calorimetric measurements}

The differential scanning calorimetry DSC measurements were carried out using a Perkin-Elmer Diamond DSC Differential Scanning Calorimeter controlled by a Thermal Analyst 2000 system. Typical sample weights used were approximately $4 \mathrm{mg}$ and were placed in sealed Aluminum pans. The heating/cooling rate of $10^{\circ} \mathrm{C} / \mathrm{min}$ was applied and upper temperature ranges of $40-190^{\circ} \mathrm{C}$ were selected. Prior to use, the calorimeter was calibrated with Indium standard $\left(\mathrm{Mp} 156.5^{\circ} \mathrm{C}\right)$. An empty Aluminum pan was used as a reference. The specimens were tested in nitrogen as an inert gas with flow rate $20.0 \mathrm{mil} / \mathrm{min}$.

\subsection{Thermogravimetric analysis (TGA)}

The thermogravimetric analysis (TGA) was performed on a NETZSCH TG 209 F1series analyzer with a heating ramp of $20^{\circ} \mathrm{C} / \mathrm{min}$ in nitrogen atmospheres in the temperature range from room temperature to $600{ }^{\circ} \mathrm{C}$.

\subsection{Dynamic mechanical analysis (DMA)}

The dynamic mechanical analysis were performed on DMA analyzer (TA Instrument Inc. USA, Q800-type) using single cantilever mode with a frequency of $1 \mathrm{~Hz}$, Ramp $3.00{ }^{\circ} \mathrm{C} / \mathrm{min}$ to $156.00{ }^{\circ} \mathrm{C}$, sinusoidal force under the direction of the sample parallel to LD.

\subsection{Scanning electron microscopy (SEM)}

The scanning electron microscopy (SEM) cryogenically fractured surfaces of the UHMWPE gel sheets were observed by S-3000N type scanning electron microscopy Hitachi, Japan. The SEM samples were gold sputtered prior to observation. 


\section{Results and Discussion}

\subsection{Mechanical tests result}

The tensile strength, modulus and elongation at break percentage after PIF processing for UHMWPE gel was clearly enhanced. The tensile strengths of the samples increased from 52 to $70.9 \%$, and the modulus increased about $84.8 \%$, where the elongation increased about $54.3 \%$. These enhancements depend on the processing conditions and the use of PIF with UHMWPE gel findings as illustrated in Table 2.

Insert Table 2 about here

Figure 3 shows stress - strain curve for UHMWPE gel samples. The high content of UHMWPE samples present higher values for the tensile and modulus when compared with the unprocessed by PIF (UnPIF) UHMWPE.

Insert Figure 3 about here

The UHMWPE samples depicted a significant values of tensile and modulus when compared with unprocessed by PIF (UnPIF) UHMWPE sample.

\subsection{DSC results}

The degree of crystallinity (Xc) was calculated using the following equation:

$$
\mathrm{X}_{\mathrm{c}}=\frac{\mathrm{H}_{\mathrm{mc}}}{\mathrm{H}} \times 100 \%
$$

Where: $\quad \mathrm{X}_{\mathrm{c}}$ is the degree of crystallinity $\%$

$\mathrm{H}_{\mathrm{mc}}$ is the melting enthalpy of crystallization of $\operatorname{HDPE}(\mathrm{J} / \mathrm{g})$

$\mathrm{H} \circ$ is the standard melting enthalpy of crystallization of $\operatorname{HDPE}(\mathrm{J} / \mathrm{g})$

In practice, the heat of fusion of pure crystalline polyethylene is taken to be in the range of $276.15-292.88 \mathrm{~J} / \mathrm{g}$, with a commonly accepted value of $288.70 \mathrm{~J} / \mathrm{g}$ Flory (1963). The degree of crystallinity and the peak melting temperature determined from DSC for the second run are summarized in Table 3, Figure 4 and Figure 5. The degree of crystallinity decreased slightly for the UHMWPE gel sheet with the increase of UHMWPE content. A small variation is observed for the melting temperature of the samples. The difference in the degree of crystallinity estimated from DSC reflects the differential result of PIF processing on the crystalline phase, interface, and amorphous phase. Table 3 presents the crystalline percent for UHMWPE gel samples.

Insert Table 3 about here

Table 3 shows that the melting temperature increased, crystalline temperature decreased as a result of use pressure-induced flow at gel state. The crystallinity of UHMWPE samples is slightly increased after pressure-induced flow processing from $35 \%$ to $59 \%$.

Insert Figure 4 and Figure 5 about here

Figure 4 and Figure 5 present the DSC melting thermograms of UHMWPE gel processed in the same conditions. The temperature of the melting of the high UHMWPE content increased slightly compared to the unprocessed by PIF UHMWPE sample. The above changes demonstrate that the presence of PIF processing in the UHMWPE gel markedly influences the crystallization and the thermal behavior of the UHMWPE component.

\subsection{TGA results}

Commonly, the use of PIF for processing UHMWPE gel was found to enhance thermal stability by acting as a re-arrangement for the UHMWPE gel molecules. The initial weight loss temperature $\left(T_{i}\right)$, the maximum weight loss temperature $\left(\mathrm{T}_{\max }\right)$, the remaining weight percent at $\left(300,450\right.$ and $\left.480^{\circ} \mathrm{C}\right)$ and DTG of UHMWPE gel have been collected in Table 3. Specifically, as can be seen in Table 3, the initial weight loss temperature $\left(T_{i}\right)$ of un-processed UHMWPE sample is about $179.7{ }^{\circ} \mathrm{C}$ where as UH4 sample is about $253.2^{\circ} \mathrm{C}$ and the maximum weight loss temperature $\left(\mathrm{T}_{\max }\right)$ of nanocomposite samples is also higher than that of the remaining samples. Particularly, $\mathrm{T}_{\max }$ of UH4 is $484.5^{\circ} \mathrm{C}$ which is higher than that UnPIF by $30.7^{\circ} \mathrm{C}$.

Insert Table 4 about here

Figure 6 and Figure 7 of TGA provides another approach to investigate the PIF effect on the thermal stability. The mass loss in the region of $150-300{ }^{\circ} \mathrm{C}$ is due to the decomposition of non volatile solvent attached on UHMWPE surface. The DTG curve of sample UHMWPE unprocessed by PIF shows two major peaks at $231^{\circ} \mathrm{C}$ and $474{ }^{\circ} \mathrm{C}$ with a shoulder around $240{ }^{\circ} \mathrm{C}$. In general, the major weight losses were observed in the range of 240 
$-490{ }^{\circ} \mathrm{C}$ and the rate of thermo-oxidative degradation of the UHMWPE gel were lower than those of UnPIF sample.

Insert Figure 6 and Figure 7 about here

UHMWPE gel samples shows peaks ranging from 477 to $489^{\circ} \mathrm{C}$. The remaining weight percent at $480{ }^{\circ} \mathrm{C}$ shows the effect of PIF processing and the UHMWPE content on the thermal stability.

\subsection{DMA results}

The dynamic mechanical properties can specify useful information about the thermal behavior of the investigated samples.

Insert Table 5 about here

From the storage modulus (É) values of the UHMWPE gel specimens that were unprocessed or processed with various UHMWPE content (Table 5). It was found that É of the Unprocessed UnPIF gel film slowly decreased with an increase in the temperature.

Insert Table 5 and Figure 8 about here

Figure 8 the storage modulus (É) as a function of temperature for the prepared samples. These samples exhibit similar decreasing (É) procedures with increasing temperature. The increase in segmental polymer chain movement with temperature was caused this behavior. The storage modulus curves of the samples have three regions: glassy, glass transition and rubbery. In the $40-80{ }^{\circ} \mathrm{C}$ rang, the dramatic (É) drop related to the glass transition region of UHMWPE, the unprocessed UnPIF gel showed the lowest modulus (É) compared to the UHMWPE processed sample.

Insert Figure 9 about here

Figure 9 shows the loss tangent $(\tan \delta$ ) versus temperature for the samples. The peak, corresponding to the glass transition temperature of UHMWPE, is perceived for each sample. By the use of PIF and the increasing of the UHMWPE contents of samples, peak temperatures (i.e., glass transition temperatures) slightly increased.

\subsection{SEM results}

Figure 10 presents the SEM images fractured surfaces perpendicular to the direction of solid flow for the UHMWPE gel samples before and after PIF processing. Compared with the relatively uniform fracture surfaces of the unprocessed sample, the samples after PIF exhibit clearly oriented structures of packed layers. Figure 10 (A, B) shows the images fractured surfaces of unprocessed sample UnPIF there was a formation of voids. These voids can affect the thermal and mechanical properties.

Insert Figure 10 about here

In the high UHMWPE content samples Figure $10(\mathrm{D}-\mathrm{F})$, the spherulites deform and align in the pressure-induced flow direction to form parallel thin layers and the lamellae in each deformed spherulites also stack into aligned structures along the PIF direction. The deformation proceeds in a more homogeneous manner which allows achieving higher strains. Figure $10(\mathrm{D}-\mathrm{F})$ shows that the gel-like layer structure is formed in the semi-crystallinity samples of UHMWPE gel with different content of UHMWPE under PIF field.

\section{Conclusion}

This study provided evidence that a significant and challenging task in understanding the advantages of the use of pressure induced flow with UHMWPE gel sheets lies in the following results:

1) The utilize of pressure induced flow (PIF) process increase the tensile, modulus and elongation percent as a result of a re-arrangement of the internal molecules of the UHMWPE gel sheet.

2) The DMA and TGA analysis indicates the thermal stability of the UHMWPE gel sample as a result of PIF processing.

3) The difference in the degree of crystallinity estimated from DSC reflects the differential result of PIF processing on the crystalline phase, interface, and amorphous phase.

4) The pressure induced flow deformation proceeds in a more homogeneous manner which allows achieving higher mechanical properties.

5) The Gel-like layer structure is formed in the semi-crystallinity samples of UHMWPE gel with different contents of UHMWPE and under the pressure induced flow field. 


\section{Acknowledgements}

The research is financed by National Natural Science Foundation of China (Grant No. 50833002 and No. 20774018).

\section{References}

Bowden P. B., Young R. (1974). Deformation mechanisms in crystalline polymers. J. Mater. Sci., 9, $2034-2051$. Flory P. J., Vrij A. (1963). Melting points of Linear-chain homologs: The normal paraffin hydrocarbons. J. Am. Chem. Soc., 85, 3548.

Galeski A., Bartczak Z., Argon A. S., Cohen R. E. (1992). Morphological alterations during texture-producing plastic plane strain compression of HDPE. Macromol., 25, 5705-5718.

Gonzalez L. J. A., Acar M. H., S. W. Ryu, Ruzette A. V. G., Mayes A. M. (2003). Low temperature processing of baroplastics by pressure induced flow. Nature, 426, $424-428$.

Hoogsteen W., Van der Hooft R. J., Postema A. R., Ten Brinke G., Pennings A. J. (1988). Gel spun PE fibres, Part 1 Influence of spinning temperature and spinline stretching on morphology and properties. J. Mater. Sci., 23, 3459-3466.

Hoogsteen W., Ten Brinke G., Pennings A. J. (1990). SAXS experiments on voids in gel-spun PE fibres. $J$. Mater. Sci., 25, 1551-1556.

Maghsoud Z., Homayuon M. (2007). Gel spinning characteristics of UHMWPE and study on fibre structure before drawing. Iran. Polym. J., 16(6), 363-373.

Morye S. S., Hine P. J., Duckett R. A., Carr D. J., Ward I. M. (1999). A comparison of the properties of hot compacted gel spun PE fibre composites with conventional gel spun PE fibre composites. Composites: Part A, 30, 649-660.

Ohta T., Takada A., Yamamura T. (1995). The ultra-drawing behaviour of UHMWPE: comparison of the gel-like spherulite pressing method and the gel-casting method. Polymer, 36, (11), 2181-2187.

Pakhomov P., Galitsyn V., Khizhnyak S., Tshmel A. (2007). The straight-chain segment length distribution in xerogels of UHMWPE, which provide high drawability of gel derived fibers. J. Appl. Polym. Sci., 105, 2984-2987.

Pakhomov P. M., Khizhnyak S., Reuter H., Galitsyn V., Tshmel A. (2003). Effect of intercrystallite straight chain segments on Young's modulus of gel spun polyethylene fibers. Polym., 44, 4651-4654.

Pennings A. J., Roukema M., Van der Veen A. (1990). Further studies on the high speed gel spinning of UHMWPE. Polym. Bull., 23, 353-359.

Pennings A. J., Van Der Hooft R. J., Postema A. R., Hoogsteen W., Ten Brinke G. (1986). Polym. Bull., 16, 167-174.

Pennings A. J., Smook J., De Boer J., Gogolewski S., Van Hutten P. F. (1983). Preparation of UHMWPE Fibres by gel-spinning/hot drawing at high spinning rates. Polym. Bull., 9, 75-80.

Ruan S. L., Gao P., Yu T.X. (2006). Ultra-strong gel-spun UHMWPE fibers reinforcement using MWCN. Polym. $J ., 47,1604-1611$.

Strobl G. (1997). The physics of polymers: Concepts for understanding their structures and behavior. New York: Springer, USA.

Thomas C., Seguela R., Detrez F., Miri V., Vanmansart C. (2009). Plastic deformation of spherulitic semi-crystalline polymers: An in situ AFM study of polybutene under tensile drawing. Polym., 50, 3714-3723.

Ward I. M. (1977). Structure and properties of oriented polymers, London: Chapman \& Hall, UK.

Weiss R. G., Terech P. (eds.) (2006). Molecular gels materials with self-sssembled fibrillar networks, pp. 253-274. Springer: Printed in the Netherlands.

Yeh J. T., Chang S. S., Wu T. W. (2008). Effect of the ultra drawing behavior of gel films of UHMwPE and LMwPE blends on their physical properties. J. Appl. Polym. Sci., 107, 854-862. 
Table 1. Materials used in this study

\begin{tabular}{|l|c|c|c|c|c|}
\hline \multicolumn{1}{|c|}{ Sample } & UnPIF & UH1 & UH2 & UH3 & UH3 \\
\hline UHMWPE wt $\%$ & 8 & 4 & 6 & 8 & 10 \\
\hline Paraffin Oil wt\% & 91.54 & 95.52 & 93.53 & 91.54 & 89.55 \\
\hline Anti Oxidant wt \%. & 0.46 & 0.48 & 0.47 & 0.46 & 0.45 \\
\hline
\end{tabular}

Table 2. The tensile strength for the UHMWPE gel samples

\begin{tabular}{|c|c|c|c|c|}
\hline Sample & $\begin{array}{c}\text { Tensile strength } \\
(\mathrm{MPa})\end{array}$ & Modulus (GPa) & Strain at yield (\%) & $\begin{array}{c}\text { Elongation at } \\
\text { break \% }\end{array}$ \\
\hline UnPIF & $8.69 \pm 0.45$ & - & $5.070 \pm 0.68$ & $101.7 \pm 4.2$ \\
\hline UH1 & $18.17 \pm 0.64$ & $0.011 \pm 0.005$ & $16.51 \pm 2.12$ & $242.5 \pm 5.6$ \\
\hline UH2 & $22.81 \pm 0.49$ & $0.020 \pm 0.005$ & $20.75 \pm 1.43$ & $256.1 \pm 7.4$ \\
\hline UH3 & $28.41 \pm 0.62$ & $0.140 \pm 0.050$ & $26.45 \pm 2.30$ & $212.4 \pm 4.2$ \\
\hline UH4 & $29.82 \pm 1.21$ & $0.260 \pm 0.160$ & $26.97 \pm 1.85$ & $222.6 \pm 4.5$ \\
\hline
\end{tabular}

Table 3. DSC crystallinity and melting temperature of UHMWPE gel samples

\begin{tabular}{|c|c|c|c|}
\hline Samples & $\mathrm{T}_{\mathrm{m}}\left({ }^{\circ} \mathrm{C}\right)$ & $\mathrm{T}_{\mathrm{c}}\left({ }^{\circ} \mathrm{C}\right)$ & $\mathrm{X}_{\mathrm{c}} \%$ \\
\hline $\mathrm{UnPIF}$ & 122.21 & 122.38 & 35.69 \\
\hline $\mathrm{UH} 1$ & 125.40 & 119.32 & 57.74 \\
\hline $\mathrm{UH} 2$ & 125.58 & 118.87 & 58.48 \\
\hline $\mathrm{UH} 3$ & 129.25 & 117.59 & 58.60 \\
\hline $\mathrm{UH} 4$ & 130.93 & 116.57 & 59.60 \\
\hline
\end{tabular}

Table 4. The TG characterization of the UHMWPE gel samples

\begin{tabular}{|c|c|c|c|c|c|c|}
\hline \multirow{2}{*}{ Sample } & \multirow{2}{*}{$\mathrm{T}_{\mathrm{i}}\left({ }^{\circ} \mathrm{C}\right)$} & \multirow{2}{*}{$\mathrm{T}_{\max }\left({ }^{\circ} \mathrm{C}\right)$} & \multicolumn{3}{|c|}{ The remaining weight (wt. \%) } & \multirow{2}{*}{$\begin{array}{c}\text { DTG } \\
\left(\% /{ }^{\circ} \mathrm{C}\right)\end{array}$} \\
\hline & & & (a) $300\left({ }^{\circ} \mathrm{C}\right)$ & (a) $450\left({ }^{\circ} \mathrm{C}\right)$ & (a) $480\left({ }^{\circ} \mathrm{C}\right)$ & \\
\hline UnPIF & 179.7 & 453.8 & 40.08 & 27.83 & - & $\begin{array}{c}231.03 / 47 \\
4.23\end{array}$ \\
\hline UH1 & 251.6 & 464.0 & 87.81 & 61.61 & 0.208 & 477.4 \\
\hline $\mathrm{UH} 2$ & 250.4 & 473.9 & 88.58 & 60.74 & 0.582 & 479.3 \\
\hline UH3 & 253.2 & 484.0 & 88.12 & 59.60 & 24.25 & 485.2 \\
\hline UH4 & 253.2 & 484.5 & 91.33 & 63.17 & 24.83 & 488.5 \\
\hline
\end{tabular}

Table 5. The DMA Storage modulus of the UHMWPE at different temperatures

\begin{tabular}{|c|c|c|c|c|c|}
\hline \multirow{2}{*}{ samples } & \multirow{2}{*}{$\mathrm{T}_{\mathrm{g}}\left({ }^{\circ} \mathrm{C}\right)$} & \multicolumn{4}{|c|}{ Storage modulus $\left(\mathrm{MPa} \times 10^{3}\right)$} \\
\cline { 3 - 6 } & & $@ 26\left({ }^{\circ} \mathrm{C}\right)$ & $@ 75\left({ }^{\circ} \mathrm{C}\right)$ & $@ 100\left({ }^{\circ} \mathrm{C}\right)$ & $@ 150\left({ }^{\circ} \mathrm{C}\right)$ \\
\hline UnPIF & 78.00 & 0.847 & 0.325 & 0.155 & 0.007 \\
\hline $\mathrm{UH} 1$ & 94.77 & 1.235 & 0.447 & 0.224 & 0.059 \\
\hline $\mathrm{UH} 2$ & 95.22 & 1.250 & 0.462 & 0.239 & 0.071 \\
\hline $\mathrm{UH} 3$ & 95.37 & 1.455 & 0.509 & 0.251 & 0.077 \\
\hline $\mathrm{UH} 4$ & 96.12 & 1.663 & 0.879 & 0.398 & 0.096 \\
\hline
\end{tabular}




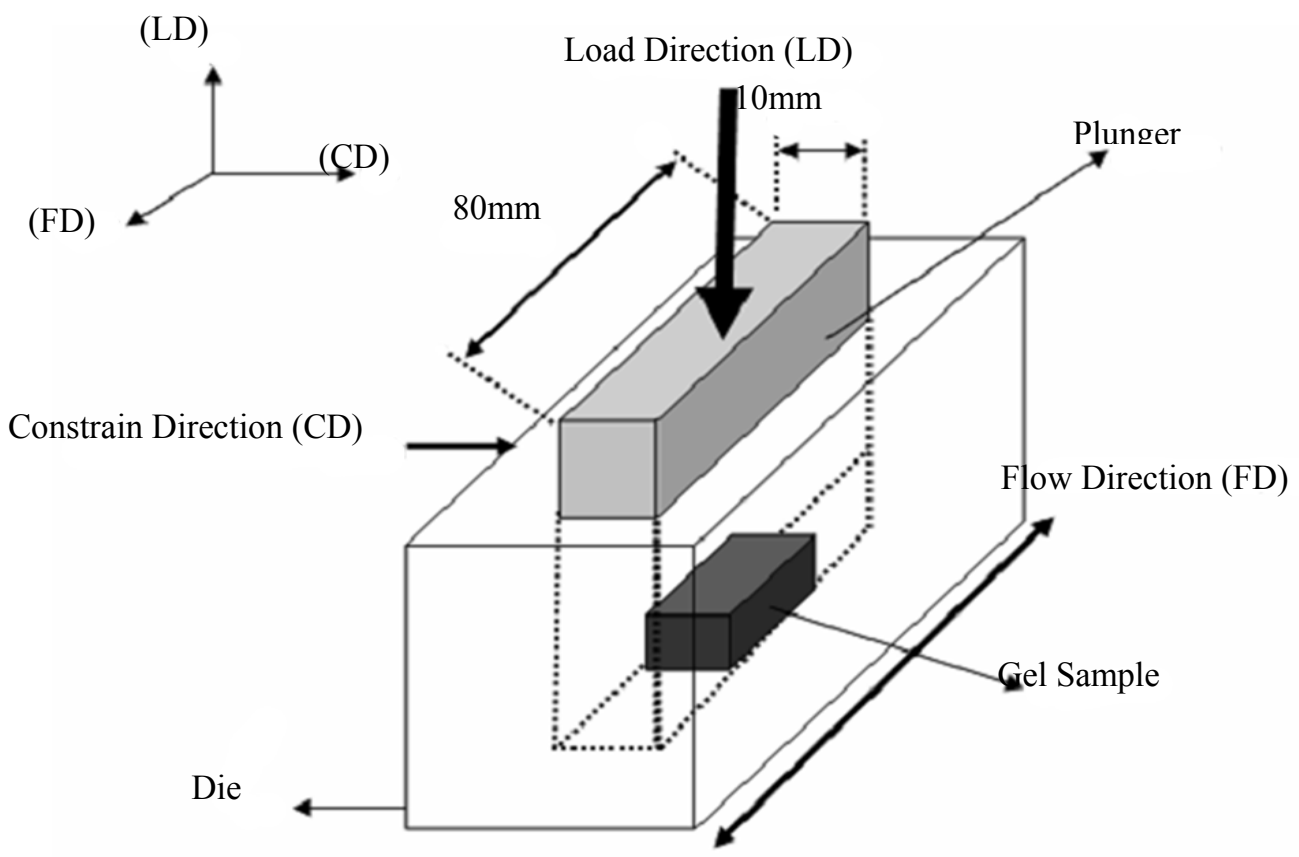

Figure 1. Illustration of a channel-die

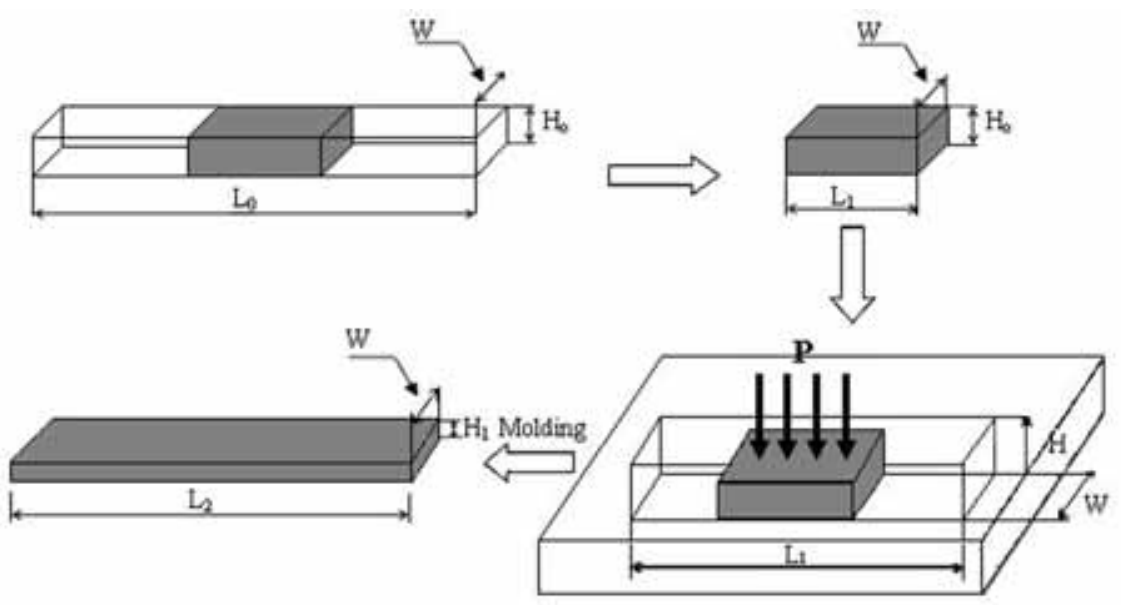

Figure 2. The PIF process of the UHMWPE gel sheet 


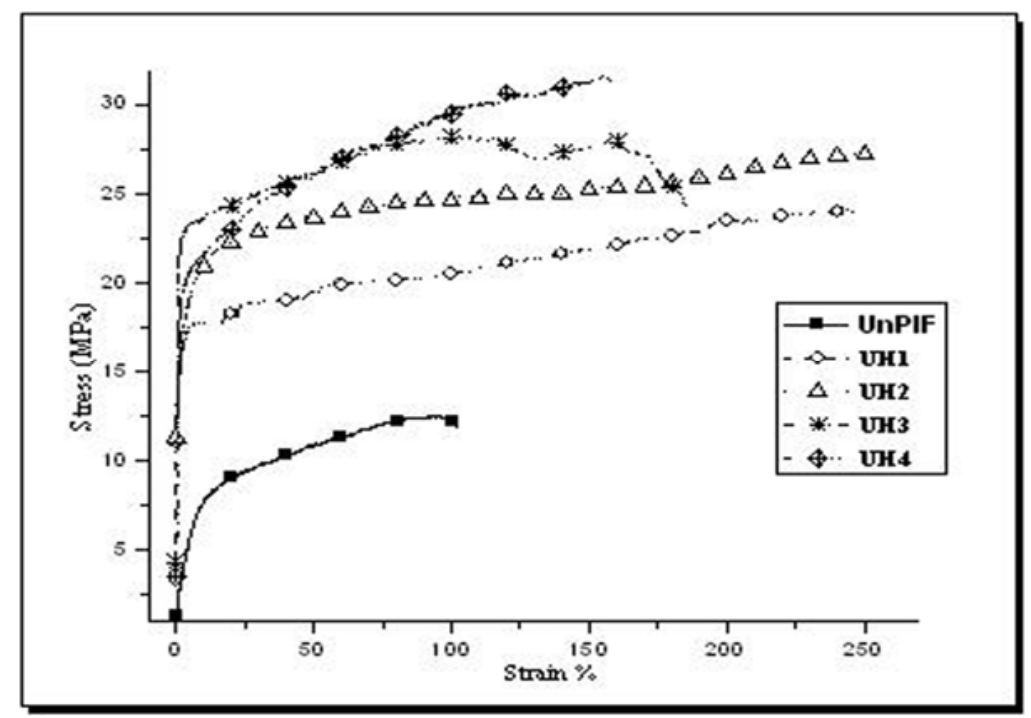

Figure 3. Stress-strain curves of UHMWPE gel before and after PIF process

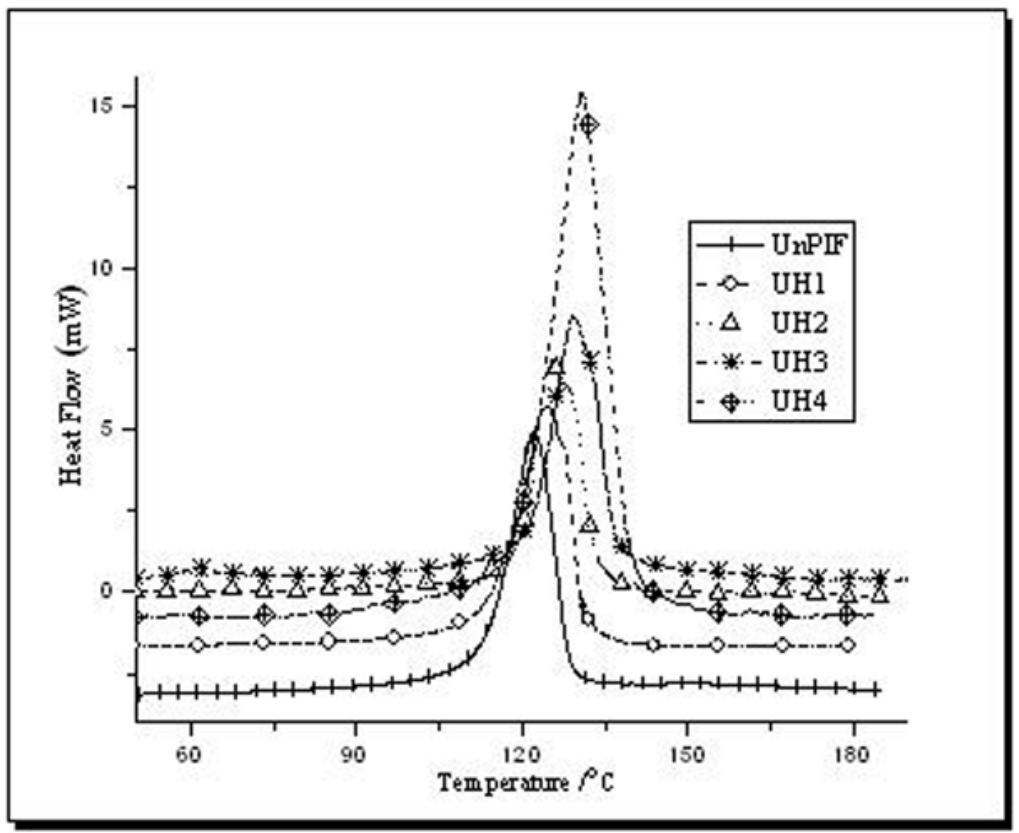

Figure 4. The DSC exothermal of UHMWPE gel before and after PIF process 


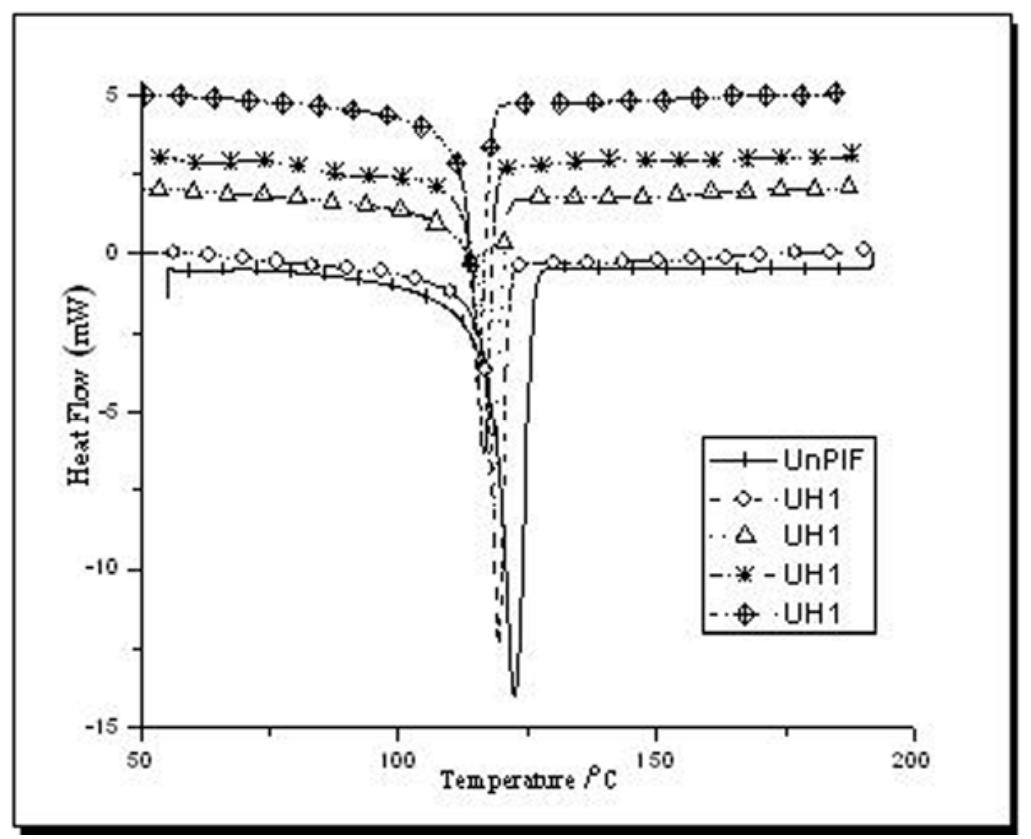

Figure 5. The DSC endothermal of UHMWPE gel before and after PIF process

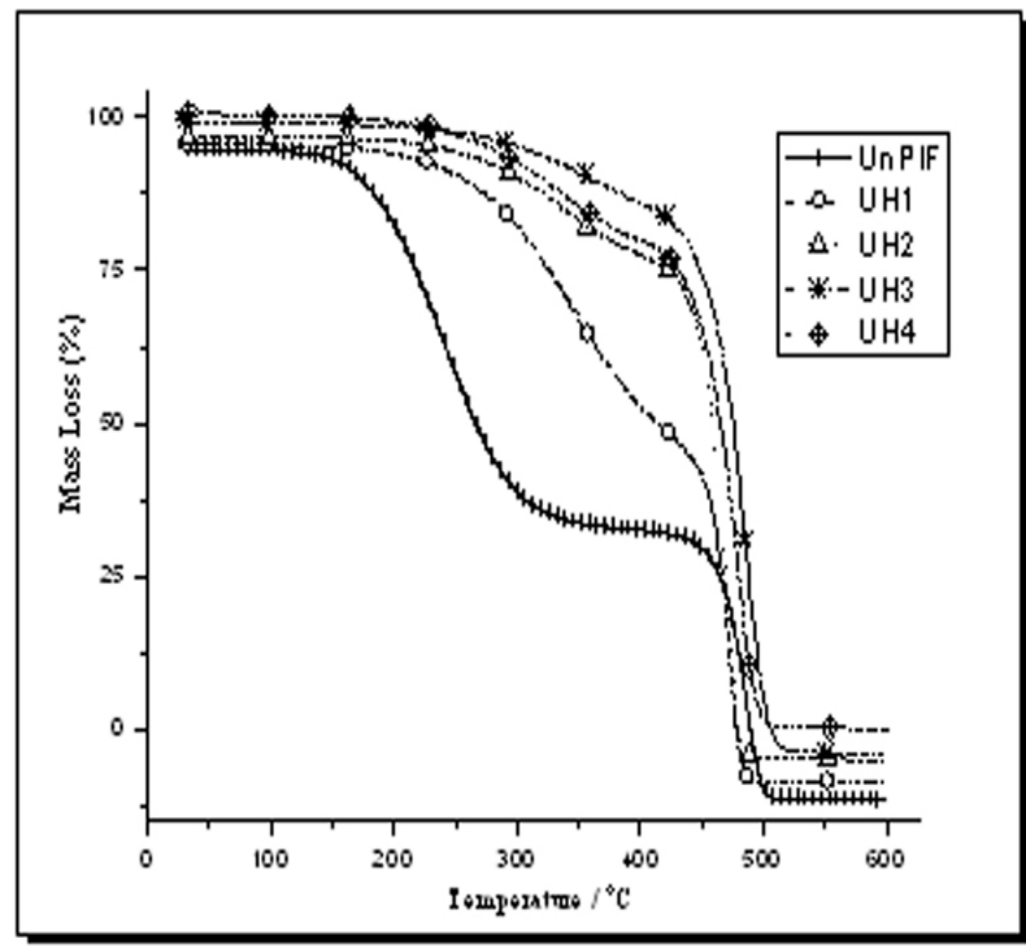

Figure 6. TGA curves under nitrogen atmosphere for UHMWPE gel before and after PIF process 


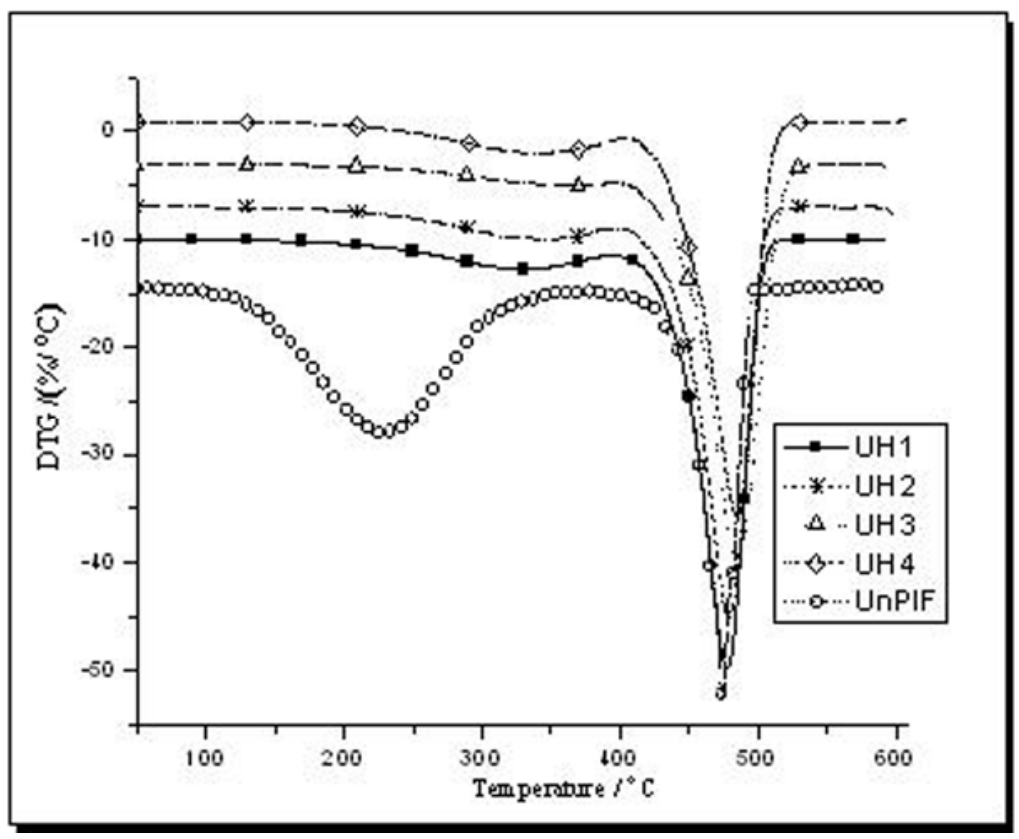

Figure 7. DTG curves under nitrogen atmosphere for UHMWPE gel before and after PIF process

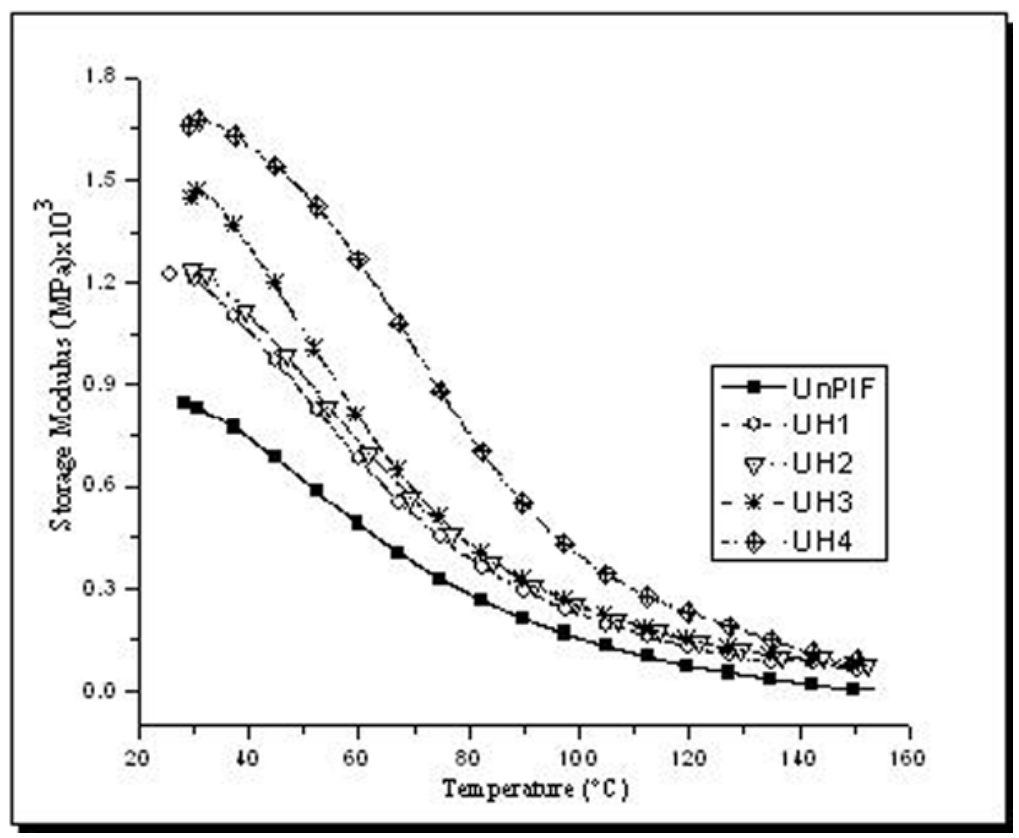

Figure 8. Storage modulus curves of UHMWPE gel before and after PIF process 


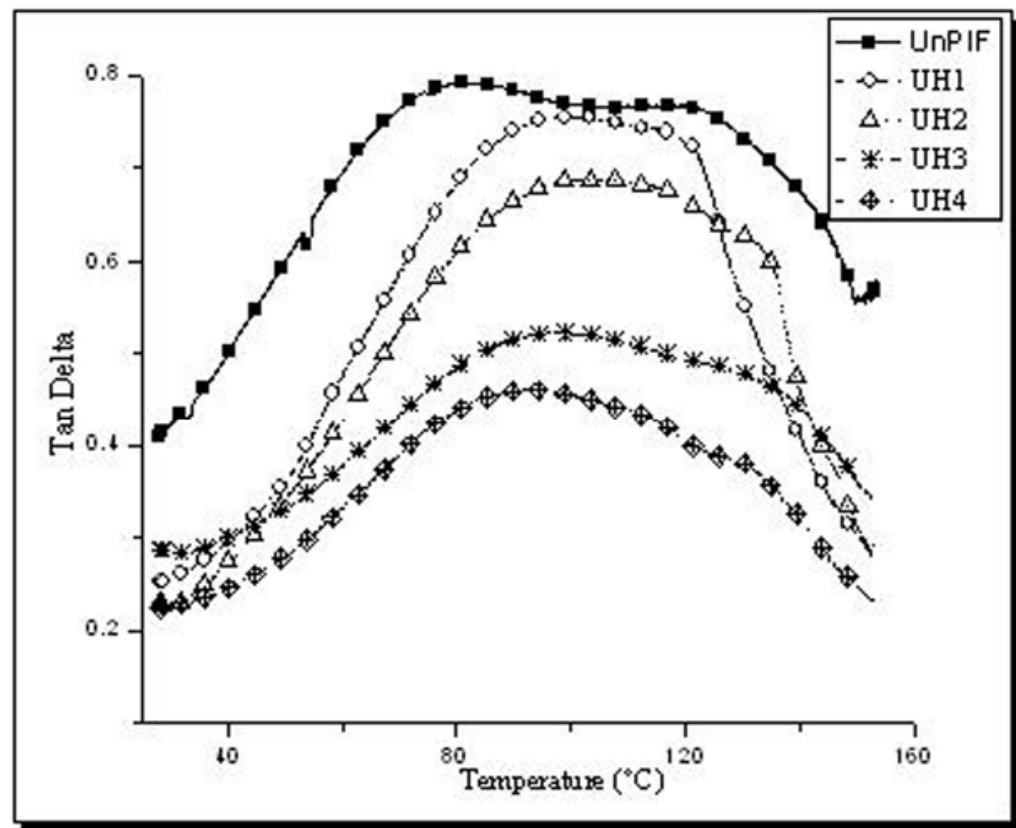

Figure 9. Tan delta curves of UHMWPE gel before and after PIF process 

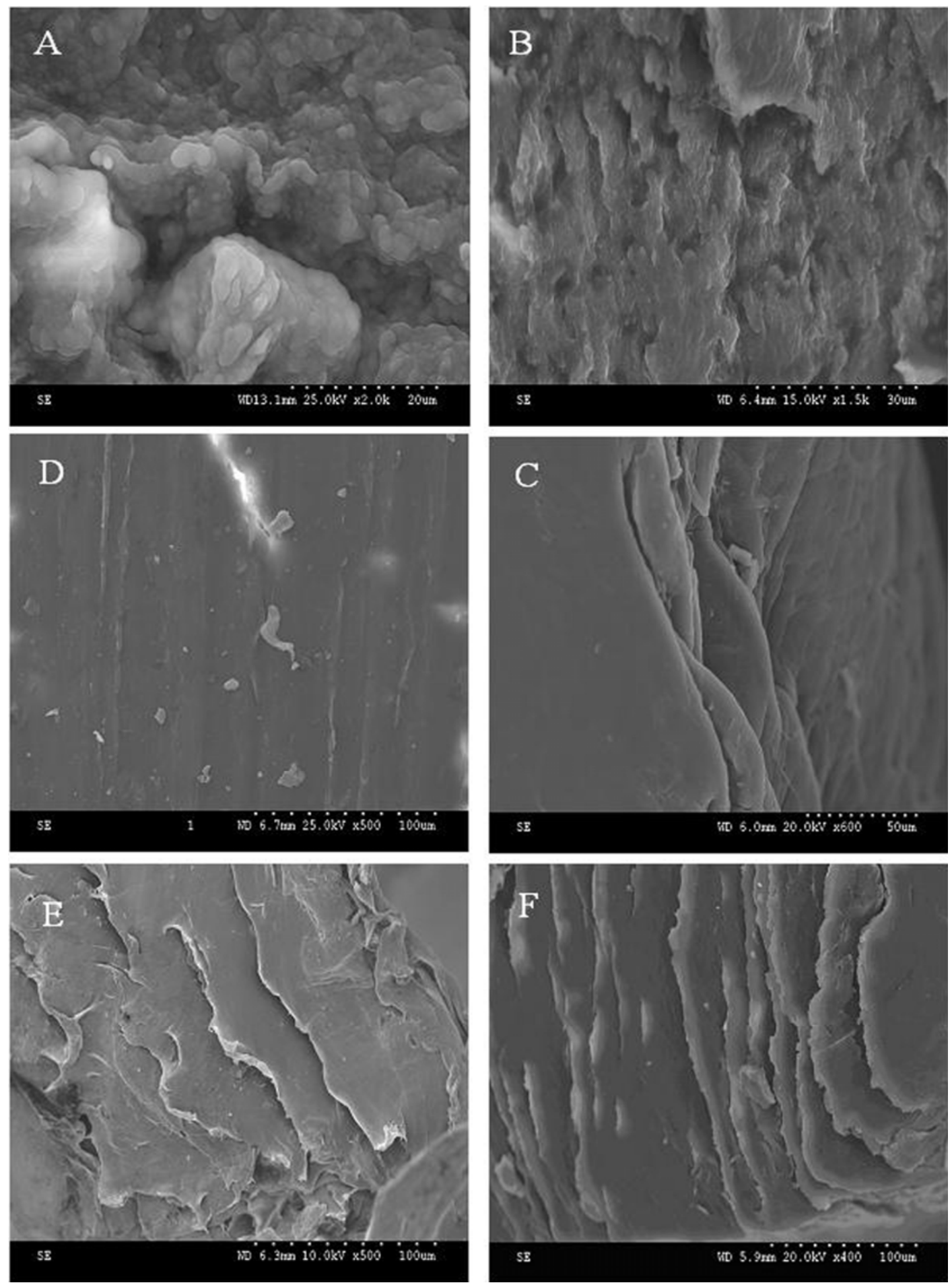

Figure 10. SEM micrographs of fracture surface of UHMWPE fabricated by gel and PIF processes (A) UnPIF 8\% UHMWPE at $2.0 \mathrm{k}$ magnification, (B) UnPIF 8\% UHMWPE at $3.0 \mathrm{k}$ magnification, (C) UH1 after PIF (D) UH2 after PIF (E) UH3 after PIF (F) UH4 after PIF 